\title{
Estudo de fibras alimentares em frutas e hortaliças para uso em nutrição enteral ou oral
}

\author{
Study of dietary fibre in fruits and vegetables for use in oral or enteral diets
}

\author{
Edma Maria de ARAÚJO ${ }^{1 *}$, Hilary Castle de MENEZES ${ }^{1}$
}

\begin{abstract}
Resumo
Dietas enterais com alimentos convencionais são usadas em nutrição domiciliar para fornecer macronutrientes, obter dietas individualizadas e de menor custo. O objetivo deste trabalho foi estudar frutas e hortaliças (alface, berinjela, cenoura, chicória, goiaba e tamarindo) como fontes de fibras alimentares solúveis e insolúveis para serem usadas em nutrição enteral ou suplemento nutricional oral. As hortaliças e frutas foram adicionadas a uma formulação enteral domiciliar e também preparadas em solução com água. Foram determinadas a composição centesimal, as fibras solúveis e insolúveis dos alimentos, a atividade de água e o pH das formulações. Foram realizados testes de gotejamento das formulações com os alimentos experimentais. A melhor proporção de alimento/dieta enteral domiciliar foi de $100 \mathrm{~g} / 2 \mathrm{~L}$ para dieta enteral e de $150 \mathrm{~g} / 2 \mathrm{~L}$ para suplemento nutricional oral (ingestão por boca). As quantidades de cada alimento adicionadas à formulação enteral equivalem a duas porções ( $100 \mathrm{~g}$ ) diárias de cada alimento para $2 \mathrm{~L}$ e $2000 \mathrm{kcal}$. A maior contribuição para aumentar a quantidade de fibras foi da goiaba e a menor, da berinjela. Os valores de atividade de água ficaram entre 0,95 e 1,00, indicando que as dietas são susceptíveis à contaminação microbiana. Nessas condições, devem ser consumidas imediatamente após o preparo.

Palavras-chave: fibras solúveis e insolúveis; nutrição enteral; suplemento nutricional oral; atividade de água; alimentos convencionais; valor nutricional.
\end{abstract}

\begin{abstract}
Enteral diets based on conventional foods are used in domestic nutritional therapy to provide macronutrients, obtain individualised diets and to lower costs. Eggplant, carrot, chicory, lettuce, guava and tamarind were studied as sources of soluble and insoluble fibers for use in enteral diets or as oral nutritional supplements, added to a domestic enteral formulation and also prepared in aqueous solution. The following physical-chemical characteristics were determined: soluble and insoluble fibers, proximate composition, $\mathrm{pH}$ and water activity. Drip tests were carried out with the formulas containing the experimental foods and as an oral nutritional supplement the best proportion of food/ water was shown to be $150 \mathrm{~g} / 2 \mathrm{~L}$, whereas when added to the formula, the best proportion was $100 \mathrm{~g}$ food/ $2 \mathrm{~L}$ of formula. The amounts of each food added to the enteral formula were equivalent to two daily portions ( $100 \mathrm{~g}$ ) of each food per $2 \mathrm{~L}$ or $2000 \mathrm{kcal}$. Of the foods tested, the guava contributed the greatest amount of fiber and the eggplant the least. The values for water activity were between 0.95 and 1.00 , indicating that these diets should be consumed immediately after preparation.

Keywords: soluble and insoluble fibers; oral nutritional supplement; enteral nutrition; water activity; conventional foods; nutritional value.
\end{abstract}

\section{Introdução}

Dietas enterais com alimentos convencionais são usadas em terapia nutricional domiciliar para fornecer macronutrientes e obter dietas individualizadas de menor custo (SILVA et al., 2005). No entanto, mais estudos científicos são necessários para quantificar quimicamente os nutrientes, melhorar o valor nutricional das dietas naturais e obter maior confiabilidade e segurança nas formulações, bem como melhorar o teor de fibras alimentares. Em terapia nutricional enteral, as fibras são prescritas para favorecer a tolerância à formulação, prevenir complicações (CATALANI et al., 2003; NAKAO et al., 2002) e alterações da mucosa intestinal e evitar a translocação bacteriana. A presença de fibras na dieta pode modificar a microbiota intestinal e conferir maior proteção aos colonócitos. As fibras auxiliam na regularização do trânsito intestinal não só em pacientes que seguem a terapia nutricional por períodos prolongados, mas também em pacientes que apresentam diarreia importante e/ou hábito intestinal instável (ora diarreia, ora obstipação) (ARAÚJO, W. M. C.; ARAÚJO, R. A. C, 1998; ARAÚJO, R. A. C.; ARAÚJO, W. M. C., 1999; BAXTER et al., 2000; MONGEAU; BRASSARD; VERDIER, 1989).

A presença de ácidos graxos de cadeia curta, formados a partir da fermentação das fibras pelas bactérias colônicas, é também importante por que exerce efeito bactericida local, mantém a integridade das células intestinais, aumenta o fluxo sanguíneo local e favorece a absorção de sódio, além de atuar efetivamente na regularização intestinal (BAXTER, 2001).

O consumo de vegetais tem sido considerado cada vez mais importante para a saúde (IOWA, 2008), devido às suas propriedades benéficas como o auxílio na digestão, reforço

Recebido para publicação em 22/10/2007

Aceito para publicação em 30/11/2009 (002946)

${ }^{1}$ Núcleo de Estudos e Pesquisas em Alimentação - NEPA, Universidade Estadual de Campinas - UNICAMP, Rua Albert Einstein, 291, CEP 13083-852, Campinas - SP, Brasil,

E-mails: edmarau@unicamp.br; hilary@mpc.com.br

${ }^{*}$ A quem a correspondência deve ser enviada 
do sistema imunológico, manutenção da mucosa intestinal e preservação da barreira intestinal.

Neste estudo, o objetivo foi estudar fibras alimentares de algumas frutas e hortaliças como fontes de fibras e de outros elementos considerados funcionais (IOWA, 2008; SOUZA; SOUZA NETO; MAIA, 2003; VAN DUYN; PIVONKA, 2000) tais como licopeno, carotenoides e compostos fenólicos, para uso em nutrição enteral administrada por capilar, ou suplemento nutricional oral para ingestão pela boca.

\section{Material e métodos}

\subsection{Matéria-prima}

Alimentos experimentais: alface (Lactuca sativa L.); berinjela (Solanum melongewna L.), fruto jovem sem cascas e sem sementes; cenoura (Daucus.carota L.); chicória (Cichorium endivia L.); goiaba vermelha (Psidium guajava L.) sem cascas e sem sementes; e tamarindo (Tamarinous indica L.). Os alimentos (Tabela 1) foram adquiridos em supermercados de Campinas/ SP, no estágio de maturação em que são rotineiramente comercializados.

Alimentos da formulação enteral domiciliar (não industrializada) (SUNDFELD, 2000): ovo vermelho tipo médio, óleo de soja, Nidex ${ }^{\circledast}$ (maltodextrina) e proteína de soja em pó desengordurada marca Soymilke ${ }^{\oplus}$ sabor natural enriquecida com vitaminas (A, B1, B2, B6, B12, C, D, E, K, niacina, ácido pantotênico, ácido fólico e biotina), minerais (cálcio, ferro, fósforo, magnésio, zinco, cobre, iodo, sódio e manganês), maltodextrina, aroma natural de baunilha e goma guar como espessante (Tabela 1).

Todos os alimentos foram pesados em balança analítica (Scientech SA 120, Tecnal ${ }^{\circledR}$, Piracicaba, Brasil).

\subsection{Métodos}

Padronização das quantidades dos alimentos experimentais adicionados na formulação enteral domiciliar (SUNDFELD, 2000) para uso como dietas enterais (ingestão por capilar)

Como parâmetro, foi considerada uma proporção de $20 \%$ de sólidos totais (CARVALHO; COUTO; SALES, 1992) e 2000 kcal

Tabela 1. Quantidades de alimentos experimentais e de alimentos da formulação enteral domiciliar, usados para obter dietas para uso em nutrição enteral com valor calórico aproximado de $2000 \mathrm{kcal}$ e volume total de $2 \mathrm{~L}$.

\begin{tabular}{cc}
\hline $\begin{array}{c}\text { Alimentos } \\
\text { experimentais }(\mathrm{g})\end{array}$ & $\begin{array}{c}\text { Alimentos da formulação } \\
\text { enteral domiciliar }(\mathrm{g})\end{array}$ \\
\hline Alface 100 & Soymilke $^{\oplus} 200$ \\
Berinjela 100 & Ovo inteiro 50 \\
Cenoura 100 & Clara 25 \\
Chicória 100 & Óleo de soja 18 \\
Goiaba 100 & Nidex $^{\oplus} 185$ \\
Tamarindo 100 & - \\
\hline
\end{tabular}

Formulação enteral domiciliar (SUNDFELD, 2000). para um volume total de 2 L (BAXTER et al., 2000; NESTLÉ, 2007), isto sendo a quantidade diária normalmente usada em nutrição enteral.

Cada um dos alimentos experimentais foi adicionado à formulação enteral domiciliar (SUNDFELD, 2000), obtendo-se, assim, um total de seis formulações.

A padronização das quantidades dos alimentos experimentais (alface, berinjela, cenoura, chicória, goiaba e tamarindo) foi feita testando-se maiores e menores quantidades de cada um dos alimentos adicionados à formulação enteral domiciliar (SUNDFELD, 2000). Foram realizados testes de gotejamento por capilar com cada uma das dietas (ARAÚJO; MENEZES, 2006; WAITZBERG, 1985), com diferentes quantidades de alimentos, para determinar a melhor proporção e obter a maior quantidade de fibra alimentar possível.

A mesma metodologia foi utilizada para padronizar as quantidades das preparações dos alimentos experimentais com água, usados para obter dietas para uso em nutrição enteral (ingestão por capilar).

O valor nutricional das formulações enterais com os alimentos experimentais foi calculado com dados da literatura (BRASIL, 2006) e com informação nutricional da embalagem

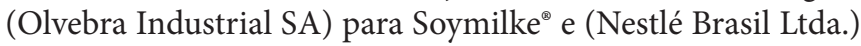
para Nidex ${ }^{\circledast}$. Foram mantidas as quantidades de Soymilke ${ }^{\bowtie}$, ovo, clara e óleo de soja da formulação para dieta enteral domiciliar (SUNDFELD, 2000). Foram acertadas as quantidades de Nidex $^{\circledast}$ e de alimentos experimentais (alface, berinjela, cenoura, chicória, goiaba e tamarindo) para obter seis dietas equilibradas com cada um dos alimentos (Tabela 2).

Padronização das quantidades dos alimentos experimentais para uso em suplemento nutricional oral (ingestão por boca)

As dietas para suplemento nutricional oral, para ingestão com o auxílio de "canudinho", foram padronizadas testando-se as quantidades de alimentos e as preparações para se estabelecer as melhores quantidades de cada alimento em relação ao volume total e para se obter a quantidade máxima de fibras (BAXTER; WAITZBERG, 2000). Os testes foram feitos preparando-se os alimentos em solução com água e com a formulação enteral domiciliar (SUNDFELD, 2000). Após o preparo, as dietas foram colocadas em copos descartáveis e testadas com "canudinhos" (canudos de plástico Pingo-lin ${ }^{\circledast}$ milk-250, com diâmetro de $5 \mathrm{~mm})$.

Todos os alimentos foram pesados em balança analítica (Scientech SA 120, Tecnal ${ }^{\oplus}$, Piracicaba, Brasil).

\section{Preparo das formulações}

As dietas foram preparadas (ARAÚJO; GALEAZZI, 1999; ARAÚJO; MENEZES, 2005, 2006) em laboratório (ambiente similar a um domicílio), em panela de pressão (12 psi, cap. $4 \mathrm{~L}$, Clock $^{\oplus}$, Brasil). Os alimentos foram cortados em pedaços pequenos, colocados em água fria e levados à cocção em fogo baixo durante 20 minutos. Em seguida, a panela foi retirada do fogo e resfriada em água fria até temperatura ambiente. 
Tabela 2. Valor nutricional das formulações enterais com os alimentos experimentais preparados com a formulação enteral domiciliar, calculados com dados da literatura e informações nutricionais das embalagens.

\begin{tabular}{lcccccc}
\hline \multicolumn{7}{c}{ Formulações experimentais } \\
\hline Formulações & Calorias $(\mathrm{kcal})$ & Proteínas $(\mathrm{g})$ & Lipídios $(\mathrm{g})$ & Carboidratos $(\mathrm{g})$ & Fibra alimentar $(\mathrm{g})$ & Cinzas $(\mathrm{g})$ \\
\hline Com alface & 1959,37 & 57,81 & 69,34 & 266,76 & 1,80 & 12,76 \\
Com berinjela & 1968,37 & 57,71 & 69,24 & 269,46 & 2,90 & 12,46 \\
Com cenoura & 1982,37 & 57,81 & 69,34 & 272,76 & 3,20 & 12,96 \\
Com chicória & 1962,37 & 57,61 & 69,24 & 267,96 & 6,20 & 12,86 \\
Com goiaba & 2002,37 & 57.61 & 69,54 & 278,06 & 6,20 & 12,56 \\
Com tamarindo & 2222,52 & 59,71 & 69,64 & 335,71 & 6,40 & 13,96 \\
\hline
\end{tabular}

Formulação enteral domiciliar (SUNDFELD, 2000); Literatura: (BRASIL, 2006); e Informações nutricionais das embalagens: [Nestlé Brasil Ltda para Nidex ${ }^{\oplus}$; Olvebra Industrial SA para Soymilke ${ }^{\oplus}$.

A preparação foi então triturada e homogeneizada em liquidificador (Migiclean, Arno ${ }^{\circ}$, São Paulo, Brasil) junto com o Soymilke ${ }^{\oplus}$ o Nidex ${ }^{\oplus}$ e o óleo, peneirada (peneira de nylon, tela plana, com aberturas de $1 \mathrm{~mm}$ de diâmetro), colocada em recipiente de vidro e mantida em refrigerador $\left(5^{\circ} \mathrm{C}\right)$ até o dia seguinte, para testes de gotejamento por capilar.

\section{Análises físico-químicas}

A homogeneidade e estabilidade das soluções foram avaliadas por inspeção visual (ARAÚJO; MENEZES, 2006; WAITZBERG, 1985). Após o preparo, as amostras foram acondicionadas em béquer de vidro e mantidas em repouso durante 24 horas à temperatura de $5{ }^{\circ} \mathrm{C}$, para depois serem analisadas.

Os testes de gotejamento (gotas/minuto) foram realizados pelo método gravitacional (ARAÚJO; MENEZES, 2006; WAITZBERG, 1985), utilizando-se $200 \mathrm{~mL}$ de dieta em frascos plásticos $\left(\right.$ Darrow $\left.^{\circ}\right)$ descartáveis, flexíveis, com capacidade de $500 \mathrm{~mL}$ e equipo (Laboratório B. Braun ${ }^{\circledR}$ ) para administração de dieta enteral.

$\mathrm{O}$ pH foi determinado em amostras de $12 \mathrm{~mL}$ (à temperatura de $23{ }^{\circ} \mathrm{C}$; amostras sem adição de óleo), utilizando-se um pHmetro (Tecnal ${ }^{\circ}-2$, Piracicaba, Brasil) (ARAÚJO; MENEZES, 2006).

\section{Composição centesimal dos alimentos experimentais}

As determinações da composição centesimal foram realizadas em duplicata, realizando-se duas repetições de cada amostra. As amostras foram liofilizadas após cocção e congelamento. Lipídios totais foram determinados pelo método de Bligh e Dyer (1959), através de extração com solventes orgânicos próprios. Em seguida, foi feita a determinação gravimétrica. $\mathrm{O}$ nitrogênio proteico foi determinado pelo método de semi-Kjeldahl (AOAC, 1984), e a proteína bruta foi calculada pela multiplicação do teor de nitrogênio pelo fator de 6,25, conforme proposto por (JONES, 1941) para frutas e vegetais. Fibras solúveis e insolúveis foram determinadas pelo tratamento com enzimas digestivas (amilase, pepsina/ pancreatina), precipitação alcoólica da fração solúvel, incineração e determinação gravimétrica (ASP et al., 1983).
A umidade foi determinada com alimentos crus em estufa a $105^{\circ} \mathrm{C}$ (IAL, 1985), e as cinzas foram quantificadas por carbonização e incineração das amostras em mufla a $550{ }^{\circ} \mathrm{C}$ (IAL, 1985). Carboidratos totais (CHOT) (g. $100 \mathrm{~g} \mathrm{~g}^{-1}$ de alimento) foram calculados por diferença: $\mathrm{CHOT}=100-$ (umidade + proteína + gordura + cinzas + FA total) (FAO, 1995). A energia metabolizável foi calculada a partir dos dados de composição centesimal. No cálculo, foram usados os fatores de conversão de $4 \mathrm{kcal}$ para carboidratos e proteínas, e de $9 \mathrm{kcal}$ para lipídios (BRASIL, 2003).

\section{Determinação da atividade de água}

As determinações da atividade de água (Aw) foram feitas por leitura direta em equipamento AquaLab CX-2 (Decagon Devices Inc., USA, 1996), acoplado a um banho termostático para manter constante a temperatura durante as medições. Logo após o preparo, as amostras das dietas ( 3 a $5 \mathrm{~mL}$ ) foram colhidas e colocadas em um porta-amostra incluído no circuito de água circulante para ajustar a temperatura a $25^{\circ} \mathrm{C}$ e, posteriormente, fazer a leitura da Aw.

\section{Resultados e discussão}

\subsection{Formulações para nutrição enteral}

Na Tabela 2, estão apresentados os dados dos valores nutricionais das dietas padronizadas com os alimentos experimentais (alface, berinjela, cenoura, chicória, goiaba e tamarindo) preparados com a formulação enteral domiciliar (SUNDFELD, 2000).

A Tabela 2 mostra o valor nutricional das dietas formuladas com os alimentos experimentais. A quantidade de cada alimento experimental adicionado à dieta enteral domiciliar (SUNDFELD, 2000), foi de $100 \mathrm{~g}$, com uma porcentagem de sólidos totais de $20 \%$, aproximadamente (CARVALHO; COUTO; SALES, 1992), e valor calórico aproximado de $2000 \mathrm{kcal}$ para um volume de $2 \mathrm{~L}$ (BAXTER et al., 2000; NESTLÉ, 2007), conforme estabelecido na metodologia.

Os testes de gotejamento gravitacional (ARAÚJO; MENEZES, 2006; WAITZBERG, 1995), com as formulações acima, resultaram em vazões de 60 a 80 gotas por minuto, que 
é um resultado de acordo com a literatura. Estes resultados permitem escoamento mais lento de dieta no período de adaptação do paciente, com aumento gradativo na vazão de acordo com as condições fisiológicas deste paciente, até que as necessidades calóricas sejam alcançadas (HSU et al., 1996).

A homogeneidade e a estabilidade das soluções apresentaram um comportamento adequado para utilização em dieta enteral (ARAÚJO; MENEZES, 2006; WAITZBERG, 1995) e para uso em suplemento nutricional oral, não apresentando sedimentação após 24 horas.

Para as soluções com alface, berinjela, cenoura, chicória, goiaba e tamarindo, preparadas em solução de água para nutrição enteral (uso por capilar), a melhor proporção foi de $100 \mathrm{~g}$ de cada um dos alimentos para um volume total de $300 \mathrm{~mL}$. Nos testes de gotejamento, essas soluções apresentaram gotejamento médio por capilar de 60 a 80 gotas/minuto (ARAÚJO; MENEZES, 2006; WAITZBERG, 1995).

As formulações nas quais os alimentos experimentais foram adicionados à dieta enteral domiciliar (SUNDFELD, 2000) apresentaram soluções mais homogêneas, quando comparadas com as formulações em que os alimentos foram preparados em solução de água. Entretanto, os alimentos preparados em solução de água podem ser aproveitados como suplemento nutricional oral.

As dietas enterais com os alimentos experimentais, preparados com a formulação enteral domiciliar (SUNDFELD, 2000), apresentaram $\mathrm{pH}$ acima de 6,0 (alface, 6,45; berinjela, 6,47; cenoura, 6,52; chicória, 6,48; goiaba, 6,12). A exceção foi o tamarindo, com pH 3,88. A dieta com o tamarindo, mais ácida e mais solúvel, não apresentou espuma após homogeneização em liquidificador.

\subsection{Formulações para suplemento nutricional oral (ingestão por boca)}

Nas preparações para suplemento nutricional oral (ingestão com "canudinho"), a quantidade adicionada de cada alimento à formulação enteral domiciliar (SUNDFELD, 2000) foi de $150 \mathrm{~g}$ para $2 \mathrm{~L}$, e a proporção alimento/água foi de $150 \mathrm{~g}$ para $300 \mathrm{~mL}$ para as preparações com água, sendo assim possível obter-se um maior teor de fibras nessas dietas (BAXTER; WAITZBERG, 2000).

O objetivo desse método foi obter dietas semelhantes às dietas líquidas industrializadas, acondicionadas em embalagens tetrapak, para uso em suplemento nutricional oral (por boca, com o auxílio de um "canudinho"), de fácil ingestão para pacientes inapetentes ou com dificuldades de deglutição.

\subsection{Resultados das análises da composição centesimal}

Na Tabela 3, estão apresentados os resultados das análises da composição centesimal dos alimentos experimentais.

Os resultados das análises da composição centesimal (Tabela 3) mostram as quantidades de fibras solúveis e insolúveis de cada alimento experimental em "base seca". A proporção de fibra alimentar variou em relação a cada um dos alimentos, sendo que a contribuição com maior quantidade foi para a goiaba, seguida da do tamarindo. No entanto, a contribuição dos outros alimentos também pode ser considerada significativa, devido à importância da presença de fibras alimentares na nutrição enteral para manter a integridade da mucosa intestinal da função absortiva, e evitar translocação bacteriana (WAITZBERG, 2004; WADA et al., 2004).

Na Tabela 4, estão apresentados os resultados da composição centesimal "base úmida".

A Tabela 4 mostra as quantidades de fibra alimentar total de cada alimento experimental (base úmida). As quantidades adicionadas à formulação enteral domiciliar (SUNDFELD, 2000) equivalem a duas porções (100 g) diárias de cada alimento para 2 L e $2000 \mathrm{kcal}$ de dieta (BAXTER et al., 2000), representando teores de fibra alimentar total (base úmida) de 1,26 g para a alface, $1,11 \mathrm{~g}$ para a berinjela, 2,01 g para a cenoura, 1,59 g para a chicória, 2,40 g para a goiaba, 3,26 g para o tamarindo. A maior contribuição para aumentar a quantidade de fibra alimentar nas formulações foi da goiaba e a menor, da berinjela. O conteúdo de fibras alimentares de uma formulação enteral industrializada varia entre 4 e $20 \mathrm{~g}$ de fibras por litro (BAXTER et al., 2000). Nas dietas com os alimentos experimentais, foram acrescentados alguns valores menores. Entretanto, sabe-se que as dietas formuladas com alimentos in natura apresentam maior viscosidade (MITNE, 2000), o que dificulta a inclusão de maiores quantidades de alimentos fonte de fibras nessas dietas.

Com dados atualizados de composição centesimal, a inclusão desses alimentos fontes de fibras nas dietas poderá ser feita com mais segurança e com melhor controle das quantidades, principalmente, por que a literatura oferece poucos dados de fibras solúveis e insolúveis para aplicação em nutrição clínica. A introdução desses alimentos na dieta enteral deve ser feita considerando-se os teores de fibra alimentar total e de fibras solúveis e insolúveis, as condições fisiológicas do paciente e a sua aceitação. Maior quantidade de fibras insolúveis para pacientes com constipação intestinal, de fibras solúveis para controle e prevenção de diarreia, e uma combinação de fibras solúveis e insolúveis que permite uma regularidade da função intestinal.

Em virtude de tamarindo ser uma fruta muito ácida, mais estudos sobre sua aceitação e tolerância deverão ser realizados antes da adição dessa fruta em nutrição clínica.

\subsection{Determinação da atividade de água}

$\mathrm{Na}$ Tabela 5, estão apresentados os resultados das análises de Aw dos alimentos experimentais preparados com a dieta enteral domiciliar contendo $100 \mathrm{~g}$ para $2 \mathrm{~L}$ e em solução de água com $100 \mathrm{~g}$ para $300 \mathrm{~mL}$.

Pode-se observar na Tabela 5 que os valores de Aw, tanto dos vegetais cozidos com água quanto cozidos com a dieta enteral, ficaram entre 0,989 e 0,999 . Os resultados apresentam valores elevados (CYNTHIA, 2000), mas em concordância com a literatura (BOBBIO, P. A.; BOBBIO, F. O., 2001) que considera 
Tabela 3. Composição centesimal (g.100 g ${ }^{-1}$, base seca ), média e desvio padrão dos resultados das análises químicas dos alimentos experimentais liofilizados.

\begin{tabular}{lcccccc}
\hline \multicolumn{1}{c}{ Alimentos liofilizados } \\
\hline \multicolumn{1}{c}{ Nutrientes } & Alface $(\mathrm{g})$ & Berinjela $(\mathrm{g})$ & Cenoura $(\mathrm{g})$ & Chicória $(\mathrm{g})$ & Goiaba $(\mathrm{g})$ & Tamarindo $(\mathrm{g})$ \\
\hline${ }^{1}$ Calorias $(\mathrm{kcal})$ & 285,64 & 294,73 & 299,24 & 170,05 & 289,91 & 380,83 \\
${ }^{2}$ Umidade (g) & $94,53 \pm 0,23$ & $93,51 \pm 0,04$ & $90,69 \pm 0,09$ & $93,70 \pm 0,15$ & $87,68 \pm 0,65$ & $22,09 \pm 0,56$ \\
'Proteínas (g) & $23,63 \pm 0,02$ & $14,36 \pm 0,11$ & $9,06 \pm 0,04$ & $20,17 \pm 0,22$ & $4,51 \pm 0,07$ & $5,29 \pm 0,02$ \\
${ }^{3}$ Lipídios (g) & $6,56 \pm 0,06$ & $2,29 \pm 0,16$ & $2,36 \pm 0,08$ & $5,17 \pm 0,89$ & $1,47 \pm 0,13$ & $0,71 \pm 0,06$ \\
${ }^{4}$ Carboidratos (g) & 33,02 & 54,17 & 60,44 & 35,71 & 64,66 & 88,32 \\
${ }^{3}$ Fibras insolúveis (g) & $18,79 \pm 0,69$ & $17,20 \pm 0,27$ & $11,49 \pm 0,79$ & $20,32 \pm 0,23$ & $21,77 \pm 0,91$ & $1,65 \pm 0,06$ \\
${ }^{3}$ Fibras solúveis (g) & $4,35 \pm 0,37$ & $6,56 \pm 0,14$ & $10,17 \pm 0,82$ & $5,03 \pm 0,27$ & $4,73 \pm 0,07$ & $1,44 \pm 0,06$ \\
${ }^{3}$ Cinzas (g) & $13,65 \pm 0,20$ & $5,42 \pm 0,01$ & $6,48 \pm 0,80$ & $13,60 \pm 0,12$ & $2,86 \pm 0,04$ & $2,59 \pm 0,02$ \\
\hline
\end{tabular}

${ }^{1}$ Calorias $(\mathrm{kcal})=$ proteínas e carboidratos multiplicados por 4 e lipídios por 9 (BRASIL, 2003); ${ }^{2}$ umidade: com alimentos crus; ${ }^{3}$ proteínas, lipídios, fibras e cinzas com alimentos cozidos

e liofilizados; ${ }^{4}$ carboidratos por diferença: $100 \mathrm{~g}$ (umidade + proteína + lipídios + fibra alimentar total + cinzas) (FAO, 1995).

Tabela 4. Composição centesimal (g.100 g ${ }^{-1}$, base úmida), média dos dados das análises químicas dos alimentos experimentais liofilizados.

\begin{tabular}{lccccrr}
\hline \multicolumn{1}{c}{ Alimentos liofilizados } \\
\hline Nutrientes & Alface (g) & Berinjela (g) & Cenoura (g) & Chicória (g) & Goiaba (g) & Tamarindo (g) \\
\hline${ }^{1}$ Calorias (kcal) & 15,03 & 20,82 & 27,82 & 17,10 & 35,69 & 296,75 \\
${ }^{2}$ Umidade (g) & 94,53 & 93,51 & 90,69 & 93,70 & 87,68 & 22,09 \\
${ }^{3}$ Proteínas (g) & 1,29 & 0,93 & 0,57 & 1,30 & 0,06 & 0,17 \\
${ }^{3}$ Lipídios (g) & 0,35 & 0,14 & 0,21 & 2,24 & 8,48 & 0,55 \\
${ }^{4}$ Carboidratos (g) & 1,68 & 3,96 & 5,92 & 1,59 & 3,26 & 2,97 \\
${ }^{3}$ Fibra Al. (g) & 1,26 & 1,11 & 2,01 & 0,80 & 0,35 & 2,40 \\
${ }^{3}$ Cinzas (g) & 0,89 & 0,35 & 0,60 & & 2,01 \\
\hline
\end{tabular}

${ }^{1}$ Calorias $(\mathrm{kcal})=$ proteínas e carboidratos multiplicados por 4 e lipídios por 9 (BRASIL, 2003); ${ }^{2}$ Umidade: com alimentos crus; ${ }^{3}$ Proteínas, lipídios, fibras e cinzas com alimentos cozidos e liofilizados; ${ }^{4}$ Carboidratos por diferença: $100 \mathrm{~g}$ (umidade + proteína + lipídios + fibra alimentar total + cinzas) (FAO, 1995); ${ }^{*}$ Fibra alimentar.

Tabela 5. Atividade de água das preparações com o alface, berinjela, cenoura, chicória, goiaba e tamarindo. Medições realizadas em temperatura de $25^{\circ} \mathrm{C}$ em triplicata.

\begin{tabular}{lcccc}
\hline \multicolumn{1}{c}{ Dietas } & Aw1 & Aw2 & Aw3 & $\bar{A} w \pm \Delta$ Aw \\
\hline Alface + água & 0,999 & 0,999 & 0,998 & $0,999 \pm 0,001$ \\
Alface + dieta & 0,999 & 0,998 & 0,997 & $0,998 \pm 0,001$ \\
Berinjela + água & 0,999 & 1,001 & 0,998 & $0,999 \pm 0,002$ \\
Berinjela + dieta & 0,995 & 0,996 & 0,994 & $0,995 \pm 0,001$ \\
Cenoura + água & 0,999 & 0,999 & 0,998 & $0,999 \pm 0,001$ \\
Cenoura + dieta & 0,991 & 0,995 & 0,996 & $0,994 \pm 0,003$ \\
Chicória + água & 0,996 & 0,992 & 0,997 & $0,995 \pm 0,003$ \\
Chicória + dieta & 0,990 & 0,993 & 0,991 & $0,991 \pm 0,002$ \\
Goiaba + água & 0,996 & 0,993 & 0,997 & $0,995 \pm 0,002$ \\
Goiaba + dieta & 0,987 & 0,992 & 0,989 & $0,890 \pm 0,003$ \\
Tamarindo + água & 0,988 & 0,989 & 0,991 & $0,989 \pm 0,002$ \\
Tamarindo + dieta & 0,990 & 0,987 & 0,992 & $0,990 \pm 0,003$ \\
\hline
\end{tabular}

Formulação enteral domiciliar (SUNDFELD, 2000).

1 o máximo aceitável para Aw. Esses resultados indicam o quanto estes alimentos são susceptíveis à contaminação microbiana. Considerando que o $\mathrm{pH}$ e a atividade de água são favoráveis ao desenvolvimento de microorganismos, a possibilidade de contaminação dessas dietas é grande. Nessas condições, os resultados indicam que as dietas devem ser consumidas imediatamente após o preparo.

\section{Conclusões}

Foi possível adicionar fibras de frutas e hortaliças às formulações para nutrição enteral ou suplemento nutricional oral, tornando esses alimentos uma opção para aumentar os teores de fibra alimentar e para uma individualização da dieta de pacientes em terapia nutricional domiciliar.

Os melhores alimentos para preparação em solução de água são a berinjela, a cenoura, a goiaba e o tamarindo.

Os valores de atividade de água mostram que as dietas são susceptíveis à contaminação microbiana. No entanto, para que os alimentos possam ser administrados e escoados por capilar, é necessário hidratação, diluição e homogeneização numa proporção média, alimento:água, de 20\%:80\%. Nessas condições, o consumo dessas dietas deve ser imediatamente após o preparo. Técnicas adequadas de higiene durante o trabalho dos manipuladores, a desinfecção de utensílios e o tratamento térmico dos alimentos são essenciais para a obtenção de um produto mais seguro.

\section{Agradecimentos}

Os autores agradecem à FAPESP - Fundação de Amparo à Pesquisa do Estado de São Paulo o auxílio financeiro ao projeto de pesquisa e à Empresa Novozymes a doação da enzima termamyl. 


\section{Referências bibliográficas}

ARAÚJO, E. M.; MENEZES, H. C. Composição centesimal, lisina disponível e digestibilidade in vitro de proteínas de fórmulas para nutrição oral ou enteral. Ciência e Tecnologia de Alimentos, v. 25, n. 4, p. 768-771, 2005.

ARAÚJO, E. M.; MENEZES, H. C. Formulações com alimentos convencionais para nutrição enteral ou oral. Ciência e Tecnologia de Alimentos, v. 26, n. 3, p. 533-538, 2006.

ARAÚJO, R. A. C.; ARAÚJO, W. M. C. Fibras alimentares. Revista Brasileira de Nutrição Clínica, v. 13, n. 3, p. 201-209, 1998.

ARAÚJO, W. M. C.; ARAÚJO, R. A. C. Alimentos funcionais. Revista Brasileira de Nutrição Clínica, v. 14, n. 4, p. 237-246, 1999.

ASP, N. G. et al. Rapid enzymatic assy of insoluble and soluble dietary fiber. Journal of Agricultural and Food Chemistry, v. 31, n. 3, p. 476-482, 1983.

ASSOCIATION OF OFFICIAL ANALYTICAL CHEMISTS - AOAC. Official methods of analysis. 14 ed. Washington, 1984. p. 1141.

BAXTER, Y. C. et al. Critérios de decisão na seleção de dietas enterais. In: WAITZBERG, D. L. (Ed.). Nutrição oral, enteral e parenteral na prática clínica. 3 ed. São Paulo: Atheneu, 2000. p. 659-676. (cap. 41)

BAXTER, Y. C. Fibras alimentares: Nutriente funcional na prevenção e tratamento da obstipação intestinal. Boletim da Sociedade Brasileira de Nutrição Parenteral e Enteral, v. 32, p. 18-19, 2001.

BAXTER, Y. C.; WAITZBERG, D. L. Indicações e usos de suplementos nutricionais orais. In: WAITZBERG, D. L. (Ed.). Nutrição oral, enteral e parenteral na prática clínica. 3 ed. São Paulo: Atheneu, 2000. p. 543. (cap. 34)

BLIGH, E. G.; DYER, W. J. A rapid method of total lipid extraction and purification. Canadian Journal of Biochemistry and. Physiology, v. 37, n. 8, p. 911-917, 1959.

BOBBIO, P. A.; BOBBIO, F. O. Química do processamento de alimentos. 3 ed. São Paulo: Varela, 2001. p. 5-8.

BRASIL. Ministério da Saúde. Resolução RDC n. 360, de 23 de Dezembro de 2003. Aprova regulamento técnico sobre rotulagem nutricional de alimentos embalados, tornando obrigatória a rotulagem nutricional. Diário Oficial da União, Poder Executivo, Brasília, DF, 26 de Dezembro de 2003. Disponível em: <http://www. anvisa.gov.br/legis/resol/2003/rdc/360_03rdc.htm\#>. Acesso em: 13 jan. de 2008.

BRASIL. Ministério da Saúde. Tabela brasileira de composição de alimentos. 2 ed. Campinas, 2006. (versão 2)

CARVAlhO, E. B.; COUTO, C. M. F.; SALES, T. R. A. Manual de Suporte Nutricional. Rio de Janeiro: Médica e Científica Ltda, 1992. p. 41-63. (cap. 4)

CATALANI, L. A. et al. Fibras alimentares. Revista Brasileira de Nutrição Clínica, v. 18, n. 4, p. 178-182, 2003.

CYNTHIA, D. Estudo dos métodos para a medida da atividade de água. São Paulo, 2000. 195 p. Dissertação (Mestrado em Engenharia Química) - Universidade de São Paulo - USP.

FOOD AND AGRICULTURE ORGANIZATION - FAO. Informe del taller CTPD sobre produccion y manejo de datos de composicion quimica de alimentos en nutricion de america latina. Santiago do Chile, 1995. p. 36.

HSU, J. J. et al. Nasogastric enteral feeding in the management of hyperemesis gravidarum. Journal of Obstetrics and Gynecology, v. 88 , n. 3, p. 343-346, 1996.

INSTITUTO ADOLFO LUTZ - IAL. Normas analíticas. 3 ed. São Paulo, 1985. (v. 1)

IOWA STATE UNIVERSITY EXTENSION. The health value of fruits and vegetables. 2008. Disponível em: <http://www.extension. iastate.edu>. Acesso em: 22 abr. 2008.

JONES, D. B. Factors for converting percentagens of nitrogen in foods and feeds into percentage of protein. $22 \mathrm{ed}$. Washington: United States Department of Agriculture, 1941. (Circular 183)

MITNE, C. Preparações não-industrializadas para nutrição enteral. In: WAITZBERG D. L (Ed). Nutrição oral, enteral e parenteral na prática clínica. 3 ed. São Paulo: Atheneu, 2000. p. 629-640. (cap. 38)

MONGEAU, R.; BRASSARD, R.; VERDIER, P. Measurement of dietary fiber in a total diet study. Journal of Food Composition and Analysis, San Diego, v. 2, n. 4 p. 317-326, 1989.

NAKAO, M. et al. Usefulness of soluble dietary fiber for the treatment of diarrhea during enteral nutrition in elderly patiens. Nutrition, v. 18 , n. 1, p. 35-39, 2002.

NESTLÉ NUTRITION. Valor nutricional da dieta enteral Nutren 1,0 pó. 2007. Disponível em: <http://www.nestle.com.br/ healthcarenutrition/htm/produtos_infonutri_nutren10>. Acesso em: 17 maio 2007.

SILVA, A. P. A. et al. Avaliação da nutrição enteral não industriazada utilizada em hospital pediátrico. Revista Brasileira de Nutrição Clínica, v. 20, n. 3, p. 107-110, 2005.

SOUSA, P. H. M.; SOUSA NETO, M. A.; MAIA, G. A. Componentes funcionais nos alimentos. Boletim da Sociedade Brasileira de Ciência e Tecnologia de Alimentos, v. 37, n. 2, p. 127-135, 2003.

SUNDFELD, L. C. R. Manual de dietas. Campinas: UNICAMP, 2000.

UNICAMP. Universidade Estadual de Campinas. Edma Maria de Araújo; Maria Antonio Martins Galeazzi. Fórmulas para nutrição enteral com alimentos convencionais. BR. n. PI 9905419-1, 12 nov. 1999.

VAN DUYN, M. A. S.; PIVONKA, E. Overviw of the health benefits of fruit and vegetable consumption for the dietetics professinal: selected literature. Journal of the American Dietetic Association, v. 100, n. 12, p. 1511-1521, 2000.

WADA, S. et al. Nutritional effects of supplementing liquid-formula diet with dietary fiber on elderly bed-dden patients. Tohoku Journal of Experimental Medicine, v. 203, n. 1, p. 9-16, 2004.

WAITZBERG, D. L. Eficácia e tolerância de uma nova formulação dietética enteral em doentes desnutridos. Revista da Associação Médica Brasileira, v. 31, n. 11-12, p. 214-221, 1985.

WAITZBERG, D. L. Fibras em nutrição enteral. São Paulo: Nutritotal, 2004. Disponível em: <http://www.nutritotal.com.br $>$. Acesso em: 22 jan. 2004.

WAITZBERG, D. L. Nutrição enteral e parenteral na prática clínica. 2 ed. São Paulo: Atheneu, 1995. 